\title{
The uncertainty of a dynamic modulus of elasticity measuring in view of non- destructive tests of concrete compressive strength
}

\author{
Krystian Jurowski, ${ }^{*}$, Alina Kaleta, and Bronisław Krępa \\ Opole University of Technology, Faculty of Civil Engineering and Architecture, Katowicka 48 Street, \\ 45-061 Opole, Poland
}

\begin{abstract}
In this work, the evaluation of measurement uncertainty of concrete dynamic elastic modulus testing method was conducted. The dynamic test was carried out using impulse excitation and modal analysis method, which can be used to determine the compressive strength of concrete in a non-destructive way. The tests were conducted using concrete samples in order to determine the practical usefulness of the mentioned method. It has been demonstrated that the impulse excitation and modal analysis method is characterized by very good repeatability.
\end{abstract}

\section{Introduction}

The standard PN-EN ISO/IEC 17025 General requirements for the competence of testing and calibration laboratories [1] states: "A laboratory performing testing activities shall apply procedures for evaluating the uncertainty of measurement". That means the testing laboratories are obligated to estimate the uncertainties for each used method. It is very important to consider the precision of conducted measurements in order to decide if the result is valuable or not, because the confidence interval makes the result possible to interpret. Thus the evaluating of measurement uncertainty has to be a good practice in every kind of testing methods, even if the laboratory isn't accredited.

In general, uncertainty could be understood as a margin of doubt that exists about the results of measurement. It could be displayed using the width of this margin (interval) or as a confidence level. Both are used to state the true value is within that margin, with a declared confidence level [2]. The term uncertainty could be used in two meanings: to express general doubts relates to measured value, or as a parameter determining the limits of variability of measurement results [3].

The general requirements related to evaluating measurements uncertainty was developed over 25 years ago. The Comité International des Poids et Mesures (CIPM) states the lack of appropriate standards and in cooperation with national standards laboratories the guidance document was developed [4].

\footnotetext{
${ }^{*}$ Corresponding author: k.jurowski@po.opole.pl
} 
There are a few reasons which make the measurement uncertainty evaluation important. First of all, it allows to confirm whether the test result includes within the specific range (e.g. stated in standards), or not. Only if the limit value is outside the specified confidence interval, the obtained value could be classified as valid - obviously with an assumed confidence level. By analogy, the uncertainty evaluation allows to meaningful comparison of test result between laboratories or obtained using different testing methods. The reasons for estimating uncertainty are wider explained in [5].

The uncertainty also informs about the accuracy of the measurement. It has to be adjusted to the type of tested material and specification which is required to be met. The accuracy of test always could be increased, but it results in costs rising, through the more time-consuming processes or necessity of using more expensive apparatus. In practice, the reached uncertainty is a result of a compromise between demanded accuracy and costs of tests.

In accordance with generally accepted guidelines, the simplified approach to evaluate uncertainty could be described by the following schedule [6]:

- determine what exactly will be measured - directly and indirectly,

- determine the sources of uncertainty, and assign it's value for each source, depended on the appropriate probability distribution,

- calculate the standard uncertainty for each component,

- determine a contribution of each component in combined standard uncertainty,

- determine the expanded uncertainty - reported with the test result.

It should be noted the uncertainty evaluation may let to better understand the used method. Especially the uncertainty budget is the useful tool developing the testing method precision. The properly made evaluation indicates the major source of uncertainty in the used method, as well as insignificant measures. Thus it highlighted the operations which have to be improved in order to narrow the confidence interval.

In case of concrete testing, the extremely precise of testing methods are commonly unfounded, because of the natural variance of concrete properties. It is resulted by the heterogeneous nature of this material and the random arrangement of ingredients in concrete volume. Nevertheless, the mentioned above doesn't mean the evaluation of measurements uncertainty is unimportant.

In this paper, the uncertainty of the impulse excitation and modal analysis method was evaluated. It is a non-destructive method of dynamic elastic modulus testing. As it was demonstrated in earlier research [7], the described method may be successfully used in concrete testing, and also in the compressive strength estimation [8]. The conducted analysis was based on the report [9], taking into account the dynamic elastic modulus of concrete testing own results, own apparatus specification and the specificity of concrete specimens.

\section{Materials and methods}

\subsection{Materials}

To test dynamic elastic modulus a normal strength concrete was used. The composition of the concrete was as follows: cement CEM I 42,5 R - $350 \mathrm{~kg} / \mathrm{m}^{3}$, natural aggregate fraction $0 / 16 \mathrm{~mm}$, with gradation in accordance with $\mathrm{PN}-\mathrm{B} / 8806250-1830 \mathrm{~kg} / \mathrm{m}^{3}$, water -175 $\mathrm{kg} / \mathrm{m}^{3}$. The concrete was prepared, formed and cured in Building Materials Laboratory, in Department of Buildings Materials Engineering at Opole University of Technology. Test samples were cured in water at temperature $20 \pm 2^{\circ} \mathrm{C}$ in accordance with PN-EN 123902:2011 and tested at the age of 28 days. 
The three batches of concrete were prepared, and three samples were taken from each batch. The same composition of concrete was used and the efforts have been made to keep the same procedure of prepare samples, in order to minimize the influence of random properties of concrete on the uncertainty of dynamic elastic modulus measurement.

\subsection{Testing method}

\subsubsection{Method description}

The dynamic elastic modulus of the concrete beam was tested using the method based on described in EN-ISO 12680-1:2007, dedicated to refractory elements testing. The similar procedures of the impulse excitation and modal analysis method are described in standards ASTM C 215 and DIN 1048. It should be noted that the procedure corresponding to the transverse vibration mode and free-free configuration of a test sample was used.

The method is based on the relation between sample geometry, its mass, fundamental resonance frequency and elastic properties. It should be noted, the analytically derived equation (Eq. 1) linking these values is based on the assumption, that the tested sample is a rod. Thus the correction factor $(\mathrm{T})$ taking into account a finite thickness of beam and Poisson ratio is used. Eventually, the dynamic elastic modulus of a rectangular bar can be calculated as follows:

$$
E=0.9465\left(\frac{m f^{2}}{b}\right)\left(\frac{L^{3}}{t^{3}}\right) T,
$$

where: $m$ - mass of sample, $f$-fundemental resonance frequency, $b, L, t$ - respectively: width, length and heigth of sample, $T$ is the correction factor (described in detail in p.3.4).

In this research, the fundamental frequency of vibration was determined using the Fast Fourier Transform (FFT) of the beam acceleration record. The accelerometer was placed in the middle of the tested sample. The postprocessing of the recorded signal was conducted using Matlab environment.

\subsubsection{Test samples}

The concrete beam samples of $500 \mathrm{~mm}$ long, and $100 \mathrm{~mm}$ width and height were used. The samples were formed in solid steel forms which ensured high accuracy of specimen dimensions and surfaces perpendicularity.

The tested samples dimensions were measured in 14 places. The length of the beam was measured along each surface (four times), using the steel linear ruler with $1 \mathrm{~mm}$ resolution scale. The width and height were measured in three points for both opposite surfaces, using the electronic caliper with $0.01 \mathrm{~mm}$ resolution scale. The Fig. 1 presents the measurement points of tested samples. The other measure dimensions (invisible on the Fig. 1) are localized symmetrically in opposite side of the beam. The measured dimensions of testes samples are presented in Table 1 . The results of height and width measurement were rounded to $0.1 \mathrm{~mm}$ because better accuracy isn't reasonable in case of a concrete specimen measurement. 


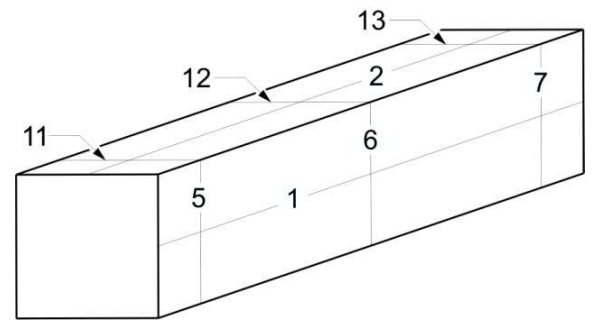

Fig. 1. The scheme of sample measuring points.

Table 1.The dimensions of the tested samples ( $\mathrm{mm})$

\begin{tabular}{|c|c|c|c|c|c|c|c|c|c|c|}
\hline \multirow{2}{*}{ Dimension } & & \multicolumn{9}{|c|}{ Sample number } \\
\hline & & 1 & 2 & 3 & 4 & 5 & 6 & 7 & 8 & 9 \\
\hline \multirow{4}{*}{ Length } & 1 & 494 & 495 & 494 & 494 & 495 & 494 & 494 & 495 & 494 \\
\hline & 2 & 494 & 496 & 494 & 494 & 495 & 494 & 494 & 494 & 494 \\
\hline & 3 & 494 & 497 & 494 & 494 & 494 & 494 & 494 & 495 & 494 \\
\hline & 4 & 494 & 497 & 494 & 494 & 494 & 494 & 494 & 495 & 494 \\
\hline \multirow{6}{*}{ Heigth } & 5 & 100.8 & 100.6 & 100.7 & 100.6 & 100.4 & 100.4 & 100.5 & 100.5 & 100.6 \\
\hline & 6 & 100.8 & 100.7 & 101.0 & 100.4 & 100.1 & 100.2 & 100.3 & 100.1 & 100.4 \\
\hline & 7 & 100.6 & 100.8 & 100.7 & 100.4 & 100.3 & 100.6 & 100.4 & 100.4 & 100.4 \\
\hline & 8 & 100.7 & 100.5 & 100.8 & 100.5 & 100.4 & 100.4 & 100.3 & 100.4 & 101.0 \\
\hline & 9 & 100.8 & 100.5 & 101.4 & 100.4 & 100.2 & 100.2 & 100.3 & 100.2 & 100.4 \\
\hline & 10 & 100.5 & 100.6 & 101.0 & 100.4 & 100.4 & 100.5 & 100.5 & 100.5 & 100.3 \\
\hline \multirow{6}{*}{ Width } & 11 & 101.0 & 100.2 & 100.5 & 100.1 & 100.9 & 99.8 & 101.1 & 101.3 & 99.8 \\
\hline & 12 & 100.0 & 100.3 & 100.9 & 99.7 & 100.2 & 100.3 & 101.1 & 100.2 & 101.3 \\
\hline & 13 & 97.5 & 100.5 & 101.2 & 100.3 & 100.4 & 100.6 & 101.1 & 99.2 & 100.9 \\
\hline & 14 & 101.1 & 100.4 & 100.5 & 99.9 & 100.6 & 100.5 & 101.0 & 101.1 & 100.3 \\
\hline & 15 & 99.9 & 100.7 & 101.0 & 99.8 & 99.9 & 100.3 & 101.0 & 100.7 & 100.9 \\
\hline & 16 & 98.9 & 101.1 & 101.3 & 100.2 & 100.9 & 100.3 & 100.9 & 100.4 & 100.9 \\
\hline
\end{tabular}

It should be noted that all samples were tested with a surface which didn't contact a formwork directed to the side. Therefore the influence of the most inaccurate dimension of the beam on test result is reduced.

\subsubsection{The test stand}

The test stand was placed on steel laboratory table. The supports were made by steel tubes distanced by $11 \mathrm{~cm}$ from each end of the tested sample - the theoretical nodes of first vibration mode (so-called free-free configuration). It aims to let sample vibrate this mode as easily as possible.

\subsubsection{Used apparatus}

Mass of samples was determined using electronic weight with an accuracy of $0.1 \mathrm{~g}$.

The accelerations of the beam were measured using PCB M352C65 accelerometer and it was recorded using the DataTranslation 9837A data Acquisition card. The mass of accelerometer is $2 \mathrm{~g}$. 


\section{The uncertainty evaluation procedure}

The uncertainty evaluation was conducted in accordance with procedure presented in the report [9] where the similar method was considered. The mentioned work is aimed to simplify, avoid ambiguity and provide a common format of the uncertainty evaluation process. It should be noted that report [9] is based on metallic materials testing and it should be adopted for the concrete, which it is a specific material.

\subsection{Parameters for which uncertainty is to be estimated}

The measurand in the considered method is the dynamic elastic modulus of concrete $(E)$. It is obvious the $E$ value isn't measured directly - its determined from other measured quantities. The list of necessary measurements with its units and symbol were presented in Table 2. The formula used to calculate the dynamic elastic modulus is as follows Eq.1.

Table 2. List of measurements, their symbols and units

\begin{tabular}{|l|c|c|}
\hline Measurements & Units & Symbol \\
\hline Mass of the beam & $\mathrm{kg}$ & $\mathrm{m}$ \\
\hline Width of the beam & $\mathrm{m}$ & $\mathrm{b}$ \\
\hline Height of the beam & $\mathrm{m}$ & $\mathrm{t}$ \\
\hline Length of the beam & $\mathrm{m}$ & $\mathrm{L}$ \\
\hline Fundamental frequency of the beam & $\mathrm{Hz}$ & $\mathrm{f}$ \\
\hline
\end{tabular}

\subsection{Sources of uncertainty}

It is necessary to consider all possible sources of uncertainty. The sources could be linked to direct measurements as well as the apparatus limitations or environmental influence. It should be noted that the list of uncertainty sources should be made individually for each method in each laboratory because it is connected to the tested material, method procedure, and apparatus type.

The list of uncertainty sources in case of the dynamic elastic modulus of concrete testing, using the impulse excitation and modal analysis method could be divided into four groups [9]: associated with a test sample (shape tolerances, operator errors in sample measuring), associated with the apparatus (support damping, accuracy of accelerometer), due to the environment (temperature and humidity fluctuations) and due to the method (incorrect calculation of correction factor $\mathrm{T}$ ).

\subsection{Types of uncertainty}

The "Guide to Expression of Uncertainty in Measurement" [6] groups the uncertainty components into two categories: type A and type B. This classification is based on their method of evaluation and isn't intended to indicate a difference in nature of components. It should be stressed that both types of uncertainties are based on the probability density function.

The Guidelines [5] states "... a Type A standard uncertainty is obtained from a probability density function derived from an observed frequency distribution, while a Type $B$ standard uncertainty is obtained from an assumed probability density function based on the degree of belief that an event will occur". In another words type A uncertainty is evaluated statistically using the results of series of experiments. If any other way is used the uncertainty is classified as Type B. In practice, limited time and money resources force laboratories to use the Type B uncertainty. 
The identified sources of uncertainty, possible in the impulse excitation and modal analysis method are presented in Table 3. The Table 3 contains also the assumed type of uncertainty its distribution and connected with its divisor.

Table 3. Uncertainty sources, type and assumed distribution

\begin{tabular}{|l|c|c|c|}
\hline Source of uncertainty & Type & Distribution & Divisor $\left(d_{i}\right)$ \\
\hline Mass of the beam & B & rectangular & $\sqrt{3}$ \\
\hline Width of the beam & B & rectangular & $\sqrt{3}$ \\
\hline Height of the beam & B & rectangular & $\sqrt{3}$ \\
\hline Length of the beam & B & rectangular & $\sqrt{3}$ \\
\hline Fundamental frequency of the beam & A & normal & 1 \\
\hline Correction factor T & B & rectangular & $\sqrt{3}$ \\
\hline Material variability & A & T-student & 1 \\
\hline
\end{tabular}

\subsection{The standard uncertainty}

The standard uncertainty commonly designated as $u$ is the standard deviation of the results for Type A uncertainty. In the considered method the uncertainty of the fundamental frequency of the beam was evaluated that way. In order to find it's value the 30 measurements of one beam was conducted, thus the standard uncertainty deviation was calculated as a standard deviation of the observations:

$$
u(f) \approx s=\sqrt{\frac{\sum\left(x_{i}-\bar{x}\right)^{2}}{n-1}}=3.6 \mathrm{~Hz} .
$$

The standard uncertainties of the mass and dimensions of the sample measurement were assumed according to calibration certificates of weight, linear ruler and caliper, thus they were calculated as Type B uncertainty.

According to EN-ISO 12680-1:2007, the correction factor $\mathrm{T}$ calculation method depends on the $\mathrm{L} / \mathrm{t}$ ratio, and it has to be calculated using the following equation:

$$
T=1+6.585\left(1+0.0752 \mu+0.8109 \mu^{2}\right)\left(\frac{t}{L}\right)^{2}-0.868\left(\frac{t}{L}\right)^{4}-J,
$$

where $\mu$ is the Poisson ratio and $J$ is defined by Eq. 4 :

$$
J=\frac{\left[8.340\left(1+0.2023 \mu+2.173 \mu^{2}\right)\left(\frac{t}{L}\right)^{4}\right]}{\left[1+6.338\left(1+0.1408 \mu+1.536 \mu^{2}\right)\left(\frac{t}{L}\right)^{2}\right]} .
$$

The standard uncertainty of the correction factor $\mathrm{T}$ was calculated as a combined uncertainty $\left(u_{c}\right)$ depended on the length and height of the beam, the Poisson ratio and also a material variability:

$$
u_{c}(T)=\sqrt{\left(\frac{\partial T}{\partial t} \cdot u(t)\right)^{2}+\left(\frac{\partial T}{\partial t} \cdot u(L)\right)^{2}+\left(\frac{\partial T}{\partial \mu} \cdot u(\mu)\right)^{2}+\left(\frac{\partial T}{\partial T} \cdot u(T)\right)^{2}} .
$$

The Poisson ratio value of tested concrete wasn't determined. It was assumed that $\mu=$ 0.2 . Because of the unknown value of Poisson ratio for the certain concrete the wide range of confidence interval was assumed $( \pm 0.05)$. The real value of $\mu$ could be determined by iterative procedure from shear modulus calculation (for example in accordance with ASTM C 215), but as the investigation shows, the Poisson ratio value has no influence for the final uncertainty of $\mathrm{T}$ correction factor (Table 4). 
Table 4. Uncertainty of the correction factor T

\begin{tabular}{|l|c|c|c|c|c|}
\hline $\begin{array}{l}\text { Source of } \\
\text { uncertainty }\end{array}$ & $\begin{array}{c}\text { Standard } \\
\text { uncertainty }\end{array}$ & Mean value & Type & Distribution & $\begin{array}{c}\text { Contribution } \\
\%\end{array}$ \\
\hline High of the beam & $0.01 \mathrm{~mm}$ & $100.51 \mathrm{~mm}$ & $\mathrm{~B}$ & rectangular & 0.2 \\
\hline Length of the beam & $1 \mathrm{~mm}$ & $494 \mathrm{~mm}$ & $\mathrm{~B}$ & rectangular & 86.1 \\
\hline Poisson ratio & 0.05 & 0.2 & $\mathrm{~B}$ & rectangular & 0.0 \\
\hline Material variability & 0.00131 & 1.271 & $\mathrm{~A}$ & normal & 13.6 \\
\hline
\end{tabular}

The values presented in Table 4 shows the major influence on the $\mathrm{T}$ correction factor uncertainty has the length of the beam measurement. It results from the relatively inaccurate measuring instrument.

The properties of concrete specimens vary, even within the same batch of concrete mix. It is caused by the complexity of hydration process, as well as a heterogeneity of concrete mix, which results in the random composition of aggregate in concrete volume. The standard uncertainty caused by material variability was calculated as the type A, thus as a standard deviation of 9 samples. The results of the dynamic elastic modulus of concrete are presented in Table 5 .

Table 5. Results of dynamic elastic modulus testing

\begin{tabular}{|c|c|c|c|c|}
\hline \multirow{2}{*}{$\begin{array}{c}\text { Specimen } \\
\text { number }\end{array}$} & \multicolumn{3}{|c|}{ Test number } & \multirow{2}{*}{ Mean value } \\
\cline { 2 - 4 } & $\mathbf{1}$ & $\mathbf{2}$ & $\mathbf{3}$ & 38.73 \\
\hline 1 & 38.41 & 38.86 & 38.91 & 37.73 \\
\hline 2 & 37.46 & 37.86 & 37.86 & 38.50 \\
\hline 3 & 38.22 & 38.47 & 38.82 & 38.87 \\
\hline 4 & 38.65 & 38.95 & 39.00 & 39.03 \\
\hline 5 & 38.95 & 39.10 & 39.05 & 39.14 \\
\hline 6 & 39.22 & 38.91 & 39.27 & 40.15 \\
\hline 7 & 39.97 & 40.29 & 40.18 & 39.92 \\
\hline 8 & 40.23 & 40.03 & 39.51 & 40.12 \\
\hline 9 & 40.07 & 40.22 & 40.07 & \\
\hline
\end{tabular}

The mean value of the dynamic elastic modulus was equal to $39.12 \mathrm{GPa}$. Each sample was tested three times, which lets to decrease the value of standard uncertainty by calculating the standard deviation of the mean values [4]:

$$
u(E) \approx s=\sqrt{\frac{\sum\left(x_{i}-\bar{x}\right)^{2}}{n(n-1)}}=0,31 \mathrm{GPa}
$$

\subsection{The combined uncertainty}

The combined uncertainty was calculated assuming the single uncertainties are uncorrelated. The uncertainty propagation law allows to calculate the $u_{c}$ value using following equation:

$$
u_{c}=\sqrt{\sum_{i=1}^{N}\left[\frac{c_{i} \cdot u_{i}\left(x_{i}\right)}{d_{i}}\right]^{2}}=0.714 \mathrm{GPa}
$$

where $c_{i}$ is the sensitivity coefficient connected with measurement $x_{i}$. The $c_{i}$ value depends on the formulae using to calculate the dynamic elastic modulus (Eq. 1), and it should be determinate using a partial derivative of this formulae. For example, the partial derivative for the mass of a sample is equal to:

$$
\frac{\partial E}{\partial m}=\partial \frac{0.9465\left(m f^{2} / b\right)\left(L^{3} / t^{3}\right) T}{\partial m}=0.9465\left(\frac{f^{2}}{b}\right)\left(\frac{L^{3}}{t^{3}}\right) T=E \frac{1}{m} \quad \rightarrow \quad c_{i}=1
$$


thus the sensitivity coefficient for the mass standard uncertainty is $c_{i}=1$. Analogically the other sensitivity coefficients were calculated. The budget of the uncertainty of dynamic elastic modulus testing is presented in Table 6 .

Table 6. Uncertainty budget for the dynamic elastic modulus of concrete testing

\begin{tabular}{|l|c|c|c|c|c|}
\hline $\begin{array}{l}\text { Source of } \\
\text { uncertainty }\end{array}$ & $\begin{array}{c}\text { Standard } \\
\text { uncertainty }\end{array}$ & $\begin{array}{c}\text { Mean } \\
\text { value }\end{array}$ & $\begin{array}{c}\text { Sensitivity } \\
\text { coefficient } \\
c_{i}\end{array}$ & $\begin{array}{c}\boldsymbol{u}_{\boldsymbol{i}} \\
\pm G P a\end{array}$ & $\begin{array}{c}\text { Contribution } \\
\%\end{array}$ \\
\hline Mass of the beam & $3.8 \mathrm{~g}$ & $11703.1 \mathrm{~g}$ & 1 & 0.0073 & 1.0 \\
\hline Width of the beam & $0.01 \mathrm{~mm}$ & $100.46 \mathrm{~mm}$ & 1 & 0.0023 & 0.3 \\
\hline Height of the beam & $0.01 \mathrm{~mm}$ & $100.51 \mathrm{~mm}$ & 3 & 0.0067 & 0.9 \\
\hline Length of the beam & $1 \mathrm{~mm}$ & $494 \mathrm{~mm}$ & 3 & 0.1372 & 19.2 \\
\hline $\begin{array}{l}\text { Fundamental } \\
\text { frequency of the beam }\end{array}$ & $3.6 \mathrm{~Hz}$ & $1531.3 \mathrm{~Hz}$ & 2 & 0.1062 & 25.8 \\
\hline Correction factor T & 0.0036 & 1.27 & 1 & 0.0631 & 8.8 \\
\hline Material variability & $0.31 \mathrm{GPa}$ & $39.12 \mathrm{GPa}$ & 1 & 0.1807 & 43.9 \\
\hline
\end{tabular}

\subsection{The expanded uncertainty}

The expanded uncertainty $(U)$ is the value given with the result of the test. It has to specify the interval in which the real value of the measurement is expected to be, with a certain probability. The properties of concrete like the dynamic elastic modulus, are subject to normal distribution. The calculated combined standard uncertainty relates to the one standard deviation, thus it states that the interval encompassing approximately $68 \%$ of the assumed distribution. In other words, the interval $39.12 \pm 0.71 \mathrm{GPa}$ contains the real value with a probability of $68 \%$.

The mentioned above interval has to be expanded to provide a higher level of confidence, by multiplying by the coverage factor $k$. The most frequently used coverage factors are $k=1,2$ or 3 which corresponds to confidence level equal to $68.3 \%, 95.4 \%$ and $99.7 \%$ respectively. In buildings materials testing the value of coverage factor is commonly assumed as $k=2$. The expanded uncertainty is equal to:

$$
U(E)=u_{c}(E) \cdot k=0.71 \cdot 2=1.42 \mathrm{GPa}
$$

Eventually, the result of dynamic elastic modulus of concrete can be presented as:

$$
E=39.1 \pm 1.4 G P a \text {, }
$$

with the description: The expanded uncertainty $U$ is obtained by multiplying the combined standard uncertainty by a coverage factor $\mathrm{k}=2$, providing the level of confidence of approximately $95 \%$.

\section{Discussion and conclusions}

In this research, there were considered the impulse excitation and modal analysis method for non-destructive testing of the dynamic elastic modulus of concrete. The evaluation of measurement uncertainty of this method shows, that in case of normal strength concrete the expanded uncertainty is equal to $\pm 1.4 \mathrm{GPa}$, which constitues the $3.6 \%$ of the obtained value.

The conducted evaluation shows that over $40 \%$ of the uncertainty is caused by the variability of material. It indicates that in case of concrete testing methods this source of uncertainty can never be omitted.

Except for the variability of material the biggest contribution in uncertainty takes the fundamental frequency of vibration and length of the specimen measure - about $26 \%$ and $19 \%$ respectively. 
The performed uncertainty budget indicates clearly which sources of uncertainty have to be improved in order to significantly reduce the expanded uncertainty. For example, if the length measure would be made using the apparatus with scale resolution of $0.1 \mathrm{~mm}$, the relative uncertainty would decrease from $3.6 \%$ to $3.0 \%$.

The investigation shows that correction factor taking into account a finite thickness of beam and Poisson ratio, in case of the relatively stocky concrete samples, also influences significantly an uncertainty budget $(9.0 \%)$.

Based on conducted investigation it has to be concluded the non-destructive, impulse excitation and modal analysis method provides a very good repeatability. The relatively fast and easy procedure makes this method useful to the identification of the dynamic elastic modulus and the compressive strength of concrete.

\section{References}

1. ISO/IEC 17025:2005 General requirements for the competence of testing and calibration laboratories,

2. K. Brich, Measurement good practice, Guide No. 36. Estimating Uncertainties in Testing, British Measurement and Testing Association (2003),

3. S. Bell, A Beginner's Guide to Uncertainty of Measurement, National Physical Laboratory, Teddington (2001),

4. J. Arendarski, Niepewność pomiarów, Oficyna Wydawnicza Politechniki Warszawskiej, Warszawa (2013) (in polish),

5. Evaluation of measurement data - Guide to the expression of uncertainty in measurement, Joint Committee for Guides in Metrology (2008),

6. Guide to Measurement Uncertainty for Construction Materials Testing. A Simplified Approach, National Association of Testing Authorities (2011),

7. K. Jurowski, S. Kokot, P. Bobra, S. Grzeszczyk, The method of dynamic elastic modulus of concrete testing using impulse excitation of vibration and the modal analysis. Inżynieria i Budownictwo, 11, 612-615 (2016),

8. K. Jurowski, S. Grzeszczyk, Non-destructive method of concrete compressive strength determine based on dynamic Young's modulus, Monografie Technologii Betonu. Stowarzyszenie Producentów Cementu, Kraków 2, 567-579 (2016) (in polish),

9. C. K. Bullough, The Determination of Uncertainties in Dynamic Young's Modulus, Standards Measurement \& Testing Project No. SMT4-CT97-2165, UNCERT COP 13: (2000). 